\title{
Editorial. El negocio publicitario en el contexto digital
}

Javier Marzal Felici Universitat Jaume I

Andreu Casero-Ripollés Universitat Jaume I

\section{Referencia de este artículo}

Marzal Felici, Javier y Casero-Ripollés, Andreu (2019). Editorial. El negocio publicitario en el contexto digital. En: adComunica. Revista Científica de Estrategias, Tendencias e Innovación en Comunicación, (18), 11-16. DOI: http://dx.doi. org/10.6035/2174-0992.2019.18.1

\section{La centralidad de la publicidad en la sociedad digital}

Desde hace bastantes años venimos sosteniendo que la publicidad constituye el discurso hegemónico por excelencia de la sociedad de la información, al tratarse de un tipo de comunicación modélica en lo que a eficacia y capacidad persuasiva se refiere. En efecto, la información en prensa, radio y televisión responde cada vez más a una concepción más próxima al entretenimiento (Thussu, 2007), en la lógica de la «sociedad del espectáculo» (González Requena, 1990), que ya anticipó Debord en 1967. El cine mainstream contemporáneo, ejemplarmente representado por los films de la factoría Marvel / Disney, se pliega absolutamente a esta lógica de la espectacularización de las representaciones (Marzal-Felici, 1999; Bordwell, 2006), como también lo hacen las series de TV transnacionales, la narrativa de los videojuegos, buena parte del fotoperiodismo contemporáneo, etc. El auge de las narrativas transmedia también representa la revolución del modelo de financiación de la creación cultural y del sistema comunicativo actual. No podemos olvidar que la publicidad, en sus más diversas formas y modalidades, es la principal fuente de financiación del entretenimiento y de la información que consumimos en la actua- 
lidad. Por tanto, nuestra preocupación por la evolución y desarrollo del negocio publicitario es constante e, incluso, recurrente como lo acredita el hecho de hemos abordado el tema de comunicación publicitaria con bastante frecuencia en los últimos años: en el número 7 (mayo de 2014), «Los medios publicitarios en el contexto actual» o en el número 14 (julio de 2017), con la temática «Transmedia y comunicación publicitaria: retos, narrativas y emociones».

Si prestamos atención a la situación del sistema mediático español y, más especialmente, del sistema valenciano, hay muchos motivos para la preocupación. Seguimos constatando que nuestro sistema mediático está profundamente marcado por el desequilibrio entre medios privados y públicos. Las corporaciones públicas están cada vez peor financiadas y, asfixiadas por las deudas, disponen de muy poco margen para la innovación, lastradas además por el control político que nuestros gobernantes se resisten a ceder. En estos días ha sido noticia la falta de liquidez de la Corporación RTVE para asumir la compra de derechos de emisión de las Olimpiadas de Tokio 2020. Y no podemos olvidar que estamos a las puertas de un nuevo apagón digital, con la expansión de la tecnología 5G, que traerá transformaciones muy importantes en el panorama de los servicios OTT, con nuevos actores de la relevancia global de Disney, Apple y Amazon, entre otros.

En la Comunidad Valenciana, seguimos de cerca y con mucho interés el desarrollo de los nuevos medios de comunicación públicos que aglutina la Corporación Valenciana de Medios de Comunicación (CVMC) y su sociedad mercantil À Punt Mèdia. Está siendo un proceso de mucha complejidad y dificultades, porque la herencia recibida es, sin lugar a dudas, terrible. Tras un primer año de notable reactivación del sector audiovisual valenciano, nos encontramos ahora con una cierta parálisis, cuyas causas tienen que ver con una manifiesta infrafinanciación, pero también a errores de gestión que deben ser solucionados con urgencia. La Mesa Sectorial del Audiovisual Valenciano (MESAV) ha manifestado esta preocupación por la evidente disminución de la actividad del sector audiovisual desde diciembre de 2018, y la falta de comunicación con la dirección de À Punt Mèdia. Hay que destacar, como lo ha hecho la MESAV, que la recuperación de los medios de comunicación públicos está siendo fundamental para la promoción de la lengua y la identidad cultural de los valencianos, y que À Punt Mèdia es un motor esencial de las industrias culturales y creativas de la Comunidad Valenciana. En este contexto, es urgente que la Corporación Valenciana de Medios de Comunicación debe potenciar vías de financiación alternativas, que pasan por atraer a los anunciantes y aumentar notablemente los ingresos por publicidad, lo que tiene una relación directa con la mejora de los datos de audiencia. Pero debemos ser realistas: si no hay un esfuerzo inversor importante por parte de la Generalitat Valenciana, será imposible que el proyecto À Punt Mèdia pueda consolidarse a corto y medio plazo. El presupuesto anual de 55 millones en la actualidad es manifiestamente insuficiente, apenas once euros de gasto medio por habitante, nos coloca a la cola de las RTV públicas autonómicas, y hace imposible consolidar el proyecto. 
Todos querríamos que nuestros nuevos medios públicos fueran capaces de atraer una fuerte inversión publicitaria, pero esto no puede ocurrir tan fácilmente, sin un auténtico apoyo institucional.

Así pues, creemos que, una vez más, la elección del tema de nuestro Informe no puede ser más oportuno en estos momentos, gracias a la coordinación de los profesores Cristina González Oñate y Carlos Fanjul Peyró, que han conseguido reunir seis investigaciones que nos parecen muy relevantes y valiosas para conocer la situación del sector publicitario y de sus tendencias evolutivas en estos tiempos, y cuyo esfuerzo queremos agradecer desde aquí.

\section{La consolidación del proyecto editorial adComunica}

En estos últimos meses hemos recibido de la Fundación Española de Cienca y Tecnología (FECYT) el sello de calidad que concede a la calidad de edición de revistas. Para el equipo editorial de la revista adComunica es, sin duda, una gran noticia porque la FECYT es una institución que merece nuestro máximo respeto ya que tiene el reconocimiento de organismos como la Comisión Nacional de Evaluación de la Actividad Investigadora (CNEAI) y que se toma en consideración en los procesos de evaluación para la acreditación del profesorado universitario como el Programa Academia de la Agencia Nacional de Evaluación de la Calidad (ANECA).

Queremos reiterar que estos logros no serían posible sin el esfuerzo de nuestros editores, y el apoyo continuado de los investigadores y profesionales que participan en este proyecto editorial, sin cuyo trabajo sería imposible mantener esta revista. Nuestra más sincera gratitud a los coordinadores de los monográficos, a los autores y evaluadores de los manuscritos presentados, a los miembros de los comités científico y editorial y, en definitiva, a todas las personas que forman parte y alimentan el proyecto editorial de la revista adComunica.

\section{Referencias}

Bordwell, David (2006). The Way Hollywood Tells It: Story and Style in Modern Movies. Berkeley: University of California Press.

Debord, Guy (2007). La sociedad del espectáculo. Valencia: Editorial Pre-Textos. González Requena, Jesús (1990). El espectáculo informativo. Madrid: Akal.

Marzal-Felici, Javier (1999). Espectáculo y atracción fílmica. La mirada cautiva del cine de acción contemporáneo. En: Nos, Eloísa y Benet, Vicente (eds.), Cuerpos en serie. La representación del cuerpo en los medios audiovisuales. Castellón: Universitat Jaume I.

Thussu, Daya Kishan (2007). News as Entertainment: The Rise of Global Infotainment. London: Sage Publishing. 
